\title{
Effect of Ligands to Toll-Like Receptors (TLR) 3, 7 and 9 on Mice Infected with Mouse Hepatitis Virus A59
}

\author{
José L. Aparicio, Maite Duhalde Vega, Lilia A. Retegui \\ Institute of Biochemistry and Biophysics (IQUIFIB, UBA-CONICET), School of Pharmacy and Biochemistry, \\ University of Buenos Aires, Buenos Aires, Argentina \\ Email: jlaparicio@qb.ffyb.uba.ar
}

Received 16 September 2014; revised 16 December 2014; accepted 10 November 2014

Copyright (C) 2014 by authors and Scientific Research Publishing Inc.

This work is licensed under the Creative Commons Attribution International License (CC BY).

http://creativecommons.org/licenses/by/4.0/

(c) (i) Open Access

\begin{abstract}
Mice infected with mouse hepatitis virus A59 (MHV-A59), an enveloped, positive-strand RNA Coronavirus, induce hepatitis, thymus involution, IgG2a-restricted hypergammaglobulinaemia, transaminase release and autoantibodies (autoAb) to liver and kidney fumarylacetoacetate hydrolase (FAH). Since Toll-like receptors (TLR) play a central role in innate immunity, we explored the effects of TLR3, 7 and 9 stimulation on MHV mouse infection. Thus, the animals were treated with Poly (I:C), Loxoribine and CpG, the respective TLR ligands. MHV-infected mice inoculated with Poly (I:C) had significant lower levels of plasma transaminases and Ig, anti-MHV Ab, and uric acid than MHV-infected animals, whereas autoAb to kidney tissue were observed. Loxoribine only produced a slight decrease of uric acid levels and serum Ig. CpG showed deleterious effects on MHV-infected mice, since survival of animals dramatically dropped to about 10\%. AutoAb to murine tissues and uric acid release were not affected, whereas transaminases and anti-MHV Ab were slightly elevated. Besides, CpG administration produced a decrease of the high levels of serum Ig induced by the virus. Therefore, results indicated that TLR3 stimulation appeared to protect the animals against the viral infection, whereas CpG aggravated its signs. Loxoribine, the TLR7 ligand, did not show major effects.
\end{abstract}

\section{Keywords}

Mouse Hepatitis Virus, Toll-Like Receptors, Autoantibodies, Uric Acid

\section{Introduction}

MHV-A59 is an enveloped, positive-strand RNA Coronavirus that triggers various mouse pathologies, including 
hepatitis, thymus involution [1], IgG2a-restricted hypergammaglobulinaemia [2] and transient demyelination [3]. We have reported the presence of autoantibodies (autoAb) to liver and kidney fumarylacetoacetate hydrolase (FAH) in sera from various mouse strains after MHV infection [4]. The autoAb recognized conformational as well as linear antigenic determinants in the enzyme, and the autoimmune response was partly related to molecular mimicry [5]-[7]. Furthermore, we have shown that the induction of the anti-FAH autoAb was associated with the MHV-induced release of some danger signals, or alarmins [8], such as uric acid and high-mobility group box protein 1 (HMGB1) [9].

To amplify the MHV actions we treated BALB/c mice with carbon tetrachloride $\left(\mathrm{CCl}_{4}\right)$ after MHV infection. The association of MHV infection with the toxic effects of $\mathrm{CCl}_{4}$ resulted in hypergammaglobulinemia and the production of autoAb to various liver and kidney proteins, producing some signs that characterize the autoimmune hepatitis (AIH) [10]. Afterward it was observed that mice from the C57BL/6 strain were more susceptible to MHV-infection than BALB/c and thus developed several signs of AIH, i.e., hypergammaglobulinaemia, autoAb to liver antigens (Ag), elevated transaminases and, interestingly, liver infiltrates. In addition, the simultaneous treatment with the adjuvant PADRE [11] augmented some signs of the AIH-like disease [12].

Toll-like receptors (TLRs) play a central role in innate immunity as they detect conserved pathogen-associated molecular patterns (PAMPs) on a range of microbes, including viruses, leading to innate immune activation and orchestration of the adaptive immune response [13]. To date, a large number of viruses have been shown to trigger innate immunity via TLR, mainly TLR3, TLR7, TLR8 and TLR9, suggesting that these receptors are likely to be important in the outcome of viral infection [13]-[16].

TLR3 was originally identified as recognizing a synthetic analogue of double-stranded RNA (dsRNA), polyinosinic-polycytidylic acid (Poly (I:C)), which could mimic viral infection and induces antiviral immune responses by promoting the production of both type I interferon and inflammatory cytokines [13]-[16].

TLR7, originally identified as recognizing imidazoquinoline derivatives such as imiquimod and resiquimod as well as guanine analogues such as Loxoribine, identifies ssRNA derived from RNA viruses such as vesicular stomatitis virus, influenza A virus and human immunodeficiency virus. TLR7 is highly expressed in plasmacytoid dendritic cells (pDC) that are able to produce large amounts of type I interferon after virus infection [13]-[16].

TLR9 recognizes unmethylated 2'-deoxyribo(cytidine-phosphate-guanosine) (CpG) DNA motifs which are common in bacteria and viruses but rare in mammalian cells. Synthetic CpG oligodeoxynucleotides function as TLR9 ligands and directly activate DC, macrophages and B cells, and drive strong TH1 responses [13]-[16].

Thus, to explore the relationship of TLR 3, 7 and 9 with MHV effects, we treated MHV-infected mice with Poly (I:C), Loxoribine and CpG, the respective TLR ligands. The results indicated that stimulation of TLR3 slightly protected the animals against the viral effects whereas CpG administration aggravated the infection signs. Loxoribine, the TLR7 ligand, did not produce major effects.

\section{Materials and Methods}

\subsection{Mice}

Specific-pathogen-free (SPF) female C57BL/6 (B6) mice from the University of La Plata, Argentina, were used at the age of 8 - 10 weeks. All animals were maintained in isolators, on standard laboratory chow, under SPF conditions until the end of the experiments, and received care in compliance with international legal requirements.

\subsection{Preparation of MHV Stock}

The NCTC 1469 adherent cell line derived from normal mouse liver was purchased from the American Type Culture Collection. Cells growing in T-75 bottles were inoculated with MHV A59 virus at a multiplicity of 1 - 5 $50 \%$ tissue infectious doses (TCID50) per cell. After an adsorption period of $1 \mathrm{~h}$ at $37^{\circ} \mathrm{C}, 15 \mathrm{ml}$ of NCTC 135 medium with $10 \%$ fetal calf serum was added to each bottle and incubated at $37^{\circ} \mathrm{C}$. Several cycles of freezing and thawing were used to release the virus $24 \mathrm{~h}$ after inoculation. The harvested virus was centrifuged at $400 \mathrm{~g}$ for $10 \mathrm{~min}$ to remove debris and the supernatant was frozen at $-70^{\circ} \mathrm{C}$ for storage. Virus titration by endpoint method was performed by inoculating serial dilutions of the MHV stock onto cell monolayers in 96-multiwell plates. After $24 \mathrm{~h}$, wells with viral cytopathic effect were counted for each dilution and titer was expressed as TCID50 [17]. 


\subsection{Viral Infection and Toll-Like Receptor Ligand Inoculation}

On day zero C57BL/6 mice were infected intraperitoneally with $10^{4}$ TCID50 of MHV-A59. As described in Gustot et al. and Hayashia et al. [18] [19], on days -3, -1, 1, 3 and 5 pre and post-infection, mice were inoculated intraperitoneally with $250 \mu \mathrm{l}$ of saline containing $180 \mu \mathrm{g}$ of Poly (I:C) (Sigma-Aldrich, St. Louis, Missouri), $150 \mu \mathrm{g}$ of 7-allyl-7,8 dihydro-8-oxoguanosine (Loxoribine, Sigma-Aldrich, St. Louis, Missouri) or $20 \mu \mathrm{g}$ of CpG (ODN 1826, Integrated DNA Technologies, San Jose, CA). As a control, another group of mice was infected only with the virus ("MHV" mice). Mice were bled by retro-orbital bleeding at 7, 20 and 50 days after infection. The animals were euthanized by cervical dislocation.

\subsection{Determination of Anti-MHV Ab by ELISA}

To test anti-MHV Ab, ELISA plates were coated with $100 \mu$ of UV-inactivated MHV-A59, $2 \times 10^{7}$ PFU/well, diluted in $0.02 \mathrm{M}$ glycine, $0.03 \mathrm{M} \mathrm{NaCl}, \mathrm{pH}$ 9.2. After overnight incubation at room temperature and washing with phosphate buffer saline containing $0.125 \mathrm{ml}$ of Tween 20 per liter (PBS-Tween), the plates were blocked 2 $\mathrm{h}$ at $37^{\circ} \mathrm{C}$ with $0.01 \mathrm{M}$ Tris, $0.13 \mathrm{M} \mathrm{NaCl}$, pH 7.4, containing 5\% of fetal calf serum (TMS-FCS), which minimizes non-specific binding. The plates were then incubated $2 \mathrm{~h}$ at $37^{\circ} \mathrm{C}$ with mouse serum diluted in TMS-FCS and after washing with PBS-Tween, the bound Ab were revealed with peroxidase-labeled goat anti-mouse IgG (Ig-PO, Santa Cruz Biotechnology, CA, USA) diluted 1:10,000 in TMS-FCS. As a substrate, orthophenylenediamine-dihydrochloride (OPD, Sigma Chemical Co, St. Louis, MO) with freshly added $\mathrm{H}_{2} \mathrm{O}_{2}$ was used. The reaction was stopped after 10 min by addition of $1 \mathrm{M} \mathrm{H}_{2} \mathrm{SO}_{4}$. The absorption was measured by ELISA reader (Metertech Inc., Taipei, Taiwan) at $490 \mathrm{~nm}$. Non-specific values of optical density were obtained in the absence of mouse serum.

\subsection{Immunoglobulin (Ig) Assays}

For total Ig determination in mouse serum, microplates (Nunc Maxi-Sorb) were coated with $100 \mu$ lof phosphate buffer saline (PBS) containing a 1:500 diluted rabbit antiserum directed against mouse Ig. The plates were blocked for $1 \mathrm{~h}$ at $37^{\circ} \mathrm{C}$ with $0.01 \mathrm{M}$ Tris, $0.13 \mathrm{M} \mathrm{NaCl}$, pH 7.4 (TMS) containing 5\% of non-fat milk (TMS-M) and were incubated with serial dilutions of mouse serum in the same medium. After $2 \mathrm{~h}$ at $37^{\circ} \mathrm{C}$ and washing with PBS containing $0.125 \mathrm{ml}$ of Tween 20 per liter (PBS-Tween), the plates were incubated for $1 \mathrm{~h}$ at $37^{\circ} \mathrm{C}$ with peroxidase-labeled goat directed against mouse IgG (Santa Cruz Biotechnology, CA, USA) diluted 1:10,000 in TMS-M. The reaction was revealed as described in the above paragraph.

\subsection{Preparation of Liver and Kidney Extracts}

Livers and kidneys from non-infected C57BL/6 mice were removed, soaked in chilled PBS and ground in an Omni Mixer Homogenizer (Omni International Inc, USA) at $4^{\circ} \mathrm{C}$ with 20 volumes of PBS containing $1 \mathrm{mM}$ phenylmethyl-sulfonyl fluoride (PMSF) and $1 \mathrm{U} \cdot \mathrm{ml}^{-1}$ of trypsin inhibitor. The homogenates were centrifuged for $10 \mathrm{~min}$ at $400 \mathrm{~g}$ and the clarified extracts kept at $-20^{\circ} \mathrm{C}$ until used. A sample of each suspension was solubilized by heating for $30 \mathrm{~min}$ at $100^{\circ} \mathrm{C}$ in $1 \mathrm{M} \mathrm{NaOH}$ and protein concentration was determined according to Bradford method [20].

\subsection{Western Blot Analysis}

Liver or kidney extracts (100 $\mu \mathrm{g}$ of protein) were submitted to 10\% SDS-PAGE and then transferred onto nitrocellulose sheets (Amersham, Buckinghamshire, UK). After reversible staining with Ponceau S to check satisfactory transfer, non-specific Ab-binding sites were blocked by incubating the sheets with $5 \%$ nonfat milk in 30 $\mathrm{mM}$ Tris, $0.14 \mathrm{M} \mathrm{NaCl}, 0.1 \%$ (v/v) Tween 20, $\mathrm{pH} 8.0$ (TBS-M-T) for $1 \mathrm{~h}$ at room temperature with shaking. The strips were then incubated overnight at $4^{\circ} \mathrm{C}$ with an Ab dilution in TBS-M-T. After several washings with TBS containing $0.1 \%(\mathrm{v} / \mathrm{v})$ Tween 20, bound Ab were revealed with peroxidase-labeled goat anti-mouse IgG (Ig-PO, Santa Cruz Biotechnology, CA, USA) diluted 1:10,000 in TBS-M-T and ECL Prime reagents (Amersham, Buckinghamshire, UK). In each experiment a negative control (pool of sera from non-treated B6 mice) and a positive control (pool of sera from MHV-infected B6 mice) were included. The apparent molecular mass (kDa) of the detected bands was determined using a wide range protein standard (BDH Laboratory Supplies Poole 
BH15 1TD, UK).

\subsection{Transaminase Determination}

Serum aspartate aminotransferase (AST) and alanine aminotransferase (ALT) were determined using the GOT (AST) and GPT (ALT) Unitest (Wiener Lab., Rosario, Argentina).

\subsection{Determination of Uric Acid Concentration in Plasma}

It was determined enzymatically using the assay kit Uricostat (Wiener Lab, Rosario, Argentina) using 1:50 diluted mouse sera as indicated by the manufacturer.

\subsection{Statistical Analysis}

Statistical significance between experimental values was calculated using the Student's $t$-test or Mann-Whitney U-test. The Kaplan-Meier method was used to compare the differences in mouse mortality rates between groups. All statistical analysis were performed using GraphPad Prism (GraphPad Software, San Diego, CA).

\section{Results}

\subsection{Serum Alanine Aminotransferase (ALT) and Aspartate Aminotransferase (AST) Values in Mice Submitted to the Various Treatments}

ALT occurs in large concentrations in the heart and liver with moderate amounts in skeletal muscle, kidneys, and pancreas, whereas AST is found in significant quantities in liver, kidney, and skeletal muscle, in decreasing order. As described before [12], we herein found that "MHV" mice exhibited elevated serum levels of ALT after 7 days of treatment (Figure 1). Loxoribine or CpG treatment of infected animals did not change those facts, but there was a significant decrease of enzyme values under Poly (I:C) administration (Figure 1). After 20 days of treatment the enzyme levels decreased and no effect of the virus or TLR ligands could be observed. In the absence of infection, no effects of TLR ligands alone were found. Analogous results were obtained for AST determination (data not shown).

\subsection{Total Immunoglobulin (Ig)}

Since MHV induces a non-specific B-cell activation [2] [12], present results indicated that "MHV" mice showed higher Ig levels than controls 20 days after infection (Figure 2). This hypergammaglobulinemia sharply decreased

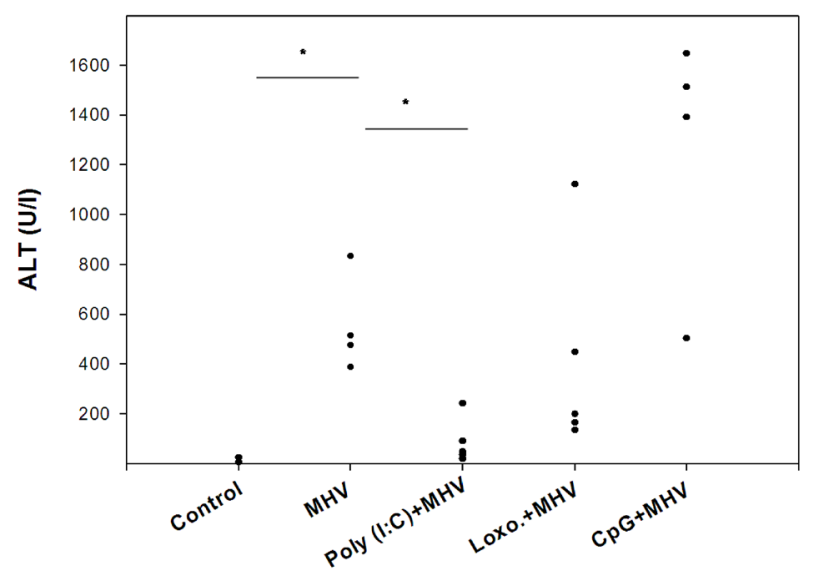

Figure 1. Levels of serum transaminases in mice submitted to the indicated treatments. ALT levels were determined in pools of sera from five animals 7 days after each treatment and/or infection. The ligands used were: Poly (I:C) (TLR 3), Loxo (Loxoribine, TLR 7) and CpG (TLR 9). MHV: animals only infected. Control: animals without any treatment or infection. Levels of ALT in mice treated only with ligand were identical to controls (data not shown). Statistical significance was calculated using the Mann-Whitney U-test. ${ }^{*} \mathrm{P}<0.05$. 


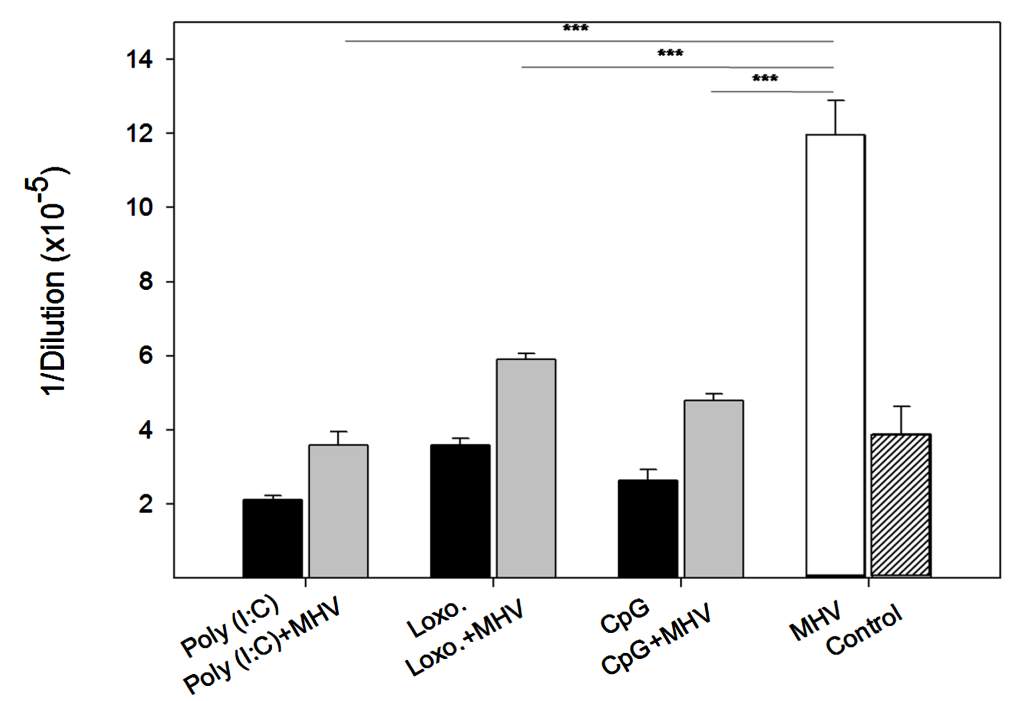

Figure 2. Concentration of total Ig in sera from mice submitted to the indicated treatments. Results were obtained with pooled sera from five mice at 20 days post infection and/or treatment. Values are expressed as the means of serum dilution to reach an OD of 1.0 at $490 \mathrm{~nm}$. The tests were done in triplicate and were repeated at least three times with similar results. Statistical significance of values was determined by Student's $t$-test in relation with MHV: ${ }^{* * *} \mathrm{P} \leq 0.001$.

after treatment of the infected animals with either Poly (I:C), Loxoribine or CpG (Figure 2). Ligands alone did not affect Ig levels compared with controls (Figure 2).

\subsection{Anti-MHV Ab}

As described before [6] [12], anti-MHV Ab are observed some time after the inoculation of the virus (Table 1). Results indicated that treatment with Poly (I:C) slightly decreased the levels of anti-MHV Ab at 20 days after infection whereas, on the contrary, administration of CpG augmented these values and Loxoribine did not produce any effect (Table 1). Besides, in the absence of infection, a single administration of each ligand did not induce $\mathrm{Ab}$ to the virus (Table 1 ).

\subsection{Auto Ab to Liver and Kidney Tissues}

Western blot results confirmed that B6 mice infected with MHV developed autoAb to liver and kidney FAH but also to various non-identified proteins (Figure 3(a) and Figure 3(b)) [12]. Molecular mass of auto-antigens recognized by pooled sera after 20 and 50 days of treatment and/or infection indicated that the most reactive ligand was Poly (I:C). Thus, this ligand induced many autoAb to kidney proteins in MHV-infected animals, compared with the sole MHV effect (Figure 3(c) and Figure 3(d)). The amount of auto-antigens detected by sera from MHV-infected mice treated with Loxoribine or CpG was not different from that displayed by serum from "MHV" animals (Figure 3(c) and Figure 3(d)). Results also showed that TLR ligands, in absence of infection, induced the production of some autoAb to liver and kidney extracts (Figure 3(c) and Figure 3(d)).

As display in Figure 3(c) and Figure 3(d), Ab to liver and kidney FAH were present in pooled sera from MHV-infected mice, treated or not with the three different ligands. To confirm those results, the putative reactivity of Ab to purified FAH, prepared as indicated in [4], was tested by Western blot. The results confirmed the absence of effect of any TLR-ligand on anti-FAH autoAb induced by MHV (data not shown).

\subsection{Uric Acid Release}

MHV-infection induces the liberation of uric acid into plasma [9] [12]. Under our experimental conditions, only Poly (I:C) and Loxoribine administration to MHV-infected animals slightly decreased uric acid release after 20 days of treatment, whereas CpG did not produce any effect (Table 2). The administration of the ligands alone did not affect uric acid concentration compared with control values (Table 2). 
a

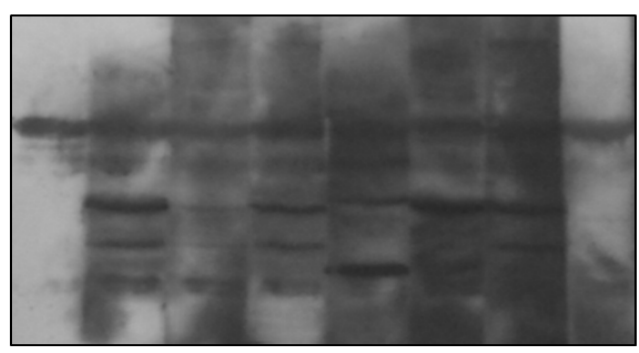

$\begin{array}{lllllllll}\mathbf{P} & \mathbf{P}+\mathbf{M} & \mathbf{L} & \mathbf{L}+\mathbf{M} & \mathbf{C} & \mathbf{C}+\mathbf{M} & \mathbf{M} & \mathbf{N}\end{array}$ b

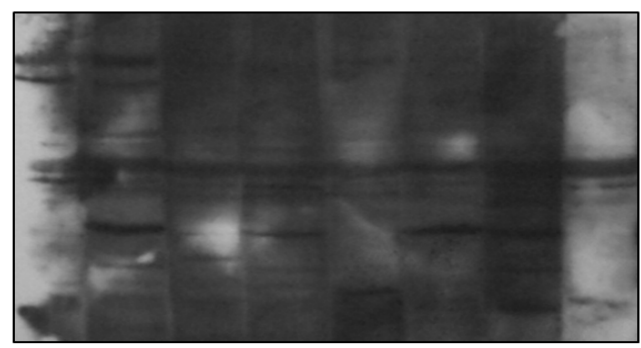

$\begin{array}{lllllll}\mathbf{P} & \mathbf{P}+\mathbf{M} & \mathbf{L} & \mathbf{L}+\mathbf{M} & \mathbf{C} & \mathbf{C}+\mathbf{M}\end{array}$

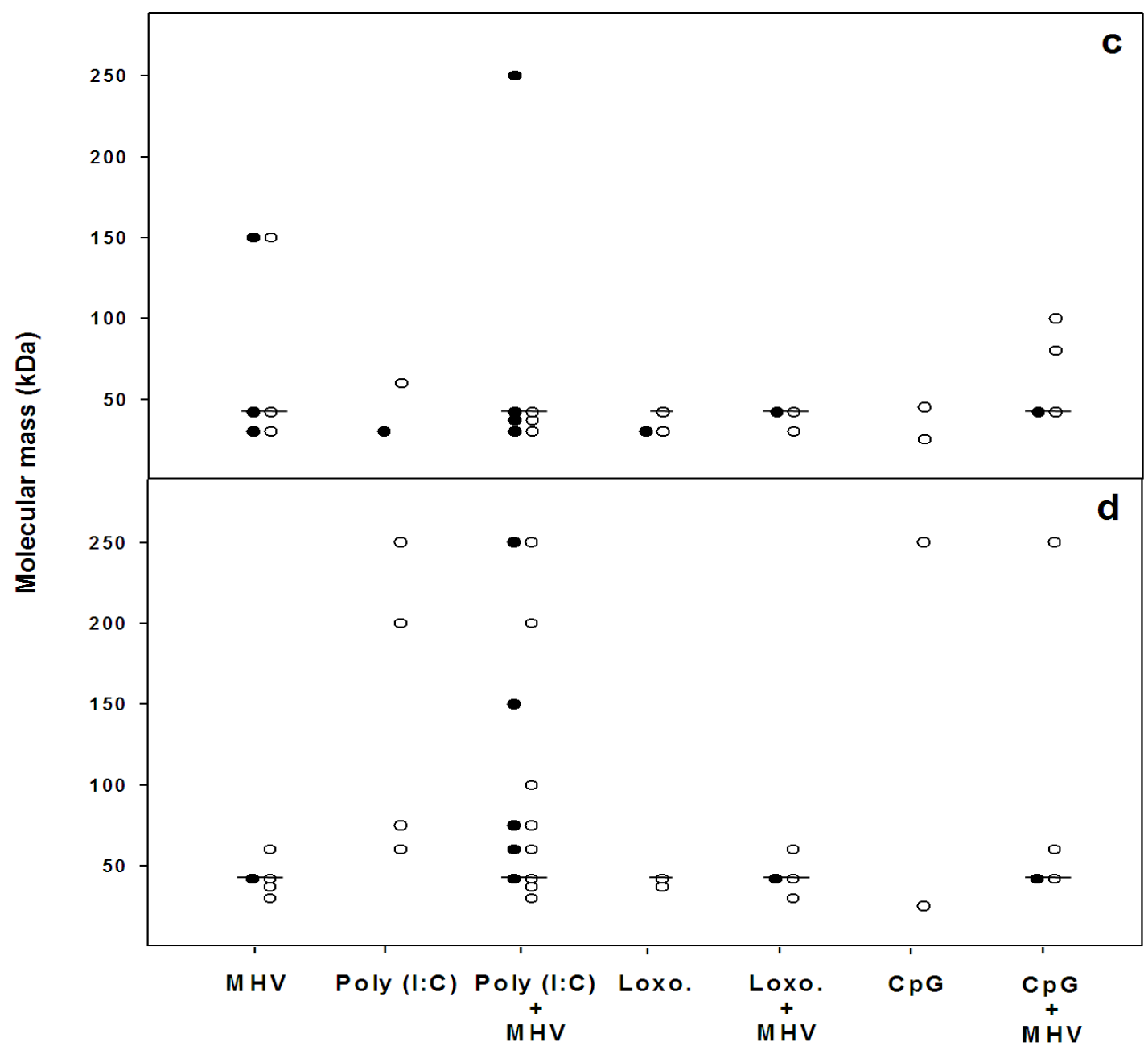

Figure 3. AutoAb to liver and kidney tissues in sera from C57BL/6 mice submitted to the indicated treatments. Upper part: Example of results obtained with mouse sera after 50 days of infection and/or treatment. Liver (a) and kidney (b) lysates were prepared as indicated in Materials and methods and separated by SDS-PAGE in $10 \%$ gels, transferred onto nitrocellulose sheets and incubated with 1:100 serum dilutions from pooled sera from five animals submitted to the indicated treatments. Bound Ab were revealed by peroxidase-labeled IgG anti-mouse IgG and ECL Plus reagents. P: Poly (I:C); L: Loxoribine; C: CpG; M: MHV; N: Control. Lower part: Summary of whole results obtained after three independent experiments. Western-blots were carried out as described above. Points indicated the molecular weights of proteins recognized by mouse sera after $20(\bullet)$ or $50(\circ)$ days post-infection and/or treatment. FAH position is shown by dashed lines. c and d: liver and kidney tissue, respectively. 
Table 1. Anti-MHV Ab in mice submitted to the different treatments and/or infection. ELISA microplates were coated with UV-inactivated MHVA59 $\left(2 \times 10^{7} \mathrm{PFU} /\right.$ well $)$ and incubated with pooled sera (diluted from 1:50 to $1: 100,000$ ) from five mice at 20 days post-treatment and/or infection. Results are expressed as the mean of three independent determinations to obtain an OD of 0.5 at $490 \mathrm{~nm}$ and statistical significance was calculated with the Student $t$-test in comparison with "MHV" animals. * $\mathrm{P}<0.05$.

\begin{tabular}{cc}
\hline Treatment & Ab titer (1/dilution) \\
Control & $3800 \pm 900$ \\
MHV & $29000 \pm 6000$ \\
Poly (I:C) & $3500 \pm 300$ \\
Poly (I:C) + MHV & $18000 \pm 1700^{*}$ \\
Loxoribine. & $8500 \pm 200$ \\
Loxoribine. + MHV & $37000 \pm 7000$ \\
CpG & $3500 \pm 150$ \\
CpG + MHV & $42000 \pm 4500^{*}$ \\
\hline
\end{tabular}

Table 2. Concentration of serum uric acid in mice submitted to the indicated treatments and/or infection Uric acid was assayed in triplicate on pooled sera from five mice, and statistical significance was calculated with the Student $t$-test in comparison with "MHV" animals. ${ }^{*} \mathrm{P}<0.05$; ${ }^{* * *} \mathrm{P}<0.005$. Control (non infected animals): $16.1 \pm 1.1$ and $17.1 \pm 1.2 \mathrm{mg} \cdot \mathrm{ml}^{-1}$ for 7 and 20 days, respectively.

\begin{tabular}{ccc}
\hline & Uric acid $\left(\mathrm{mg} \cdot \mathrm{ml}^{-1}\right)$ \\
\hline Treatment & Time after infection \\
MHV & 7 days & 20 days \\
Poly (I:C) + MHV & $14.7 \pm 0.6$ & $19.1 \pm 0.2$ \\
Loxoribine + MHV & $13.4 \pm 0.2$ & $17.2 \pm 0.4^{* * *}$ \\
CpG + MHV & $13.4 \pm 0.4$ & $16.7 \pm 1.5^{*}$ \\
\hline
\end{tabular}

\subsection{Effect of TLR-Ligands on Mouse Survival}

MHV-infection affected B6 mouse survival, since after 8 days of infection, about $60 \%$ of mice were still alive, whereas $70 \%$ of animals inoculated with Poly (I:C) survived the viral infection (Figure 4). Besides, whereas Loxoribine did not affect mouse survival, CpG aggravated the MHV harmful action, as only $11 \%$ of mice stayed alive at the end of the study. The Kaplan-Meier test was utilized to evaluate the differences in mortality rates between "MHV" mice and those inoculated with CpG $(\mathrm{P}<0.05)$ (Figure 4).

\section{Discussion}

Up to now, a large number of viruses have been shown to trigger innate immunity via TLR, suggesting that these receptors should be important in the outcome of viral infection. Thus, many viruses have evolved mechanisms not only to evade the innate immune system, but also to subvert it for their own benefit [13]. It has been described that the stimulation of TLR with their specific ligands promotes the secretion of pro-inflammatory cytokines and type 1 interferons (IFNs) [13]. Furthermore, it was demonstrated that signaling via the TLR directly or indirectly regulates the immunosuppressive function of Treg cells $\mathrm{CD} 4^{+}-\mathrm{CD} 25^{+}$in graft rejection, autoimmune or infectious diseases, and cancer [21].

To study the role of TLR 3, 7 and 9 on our model of MHV-infection and autoimmune response [9] [12], C57BL/6 mice were infected with MHV and treated with Poly (I:C), the ligand for the TLR3, Loxoribine to 


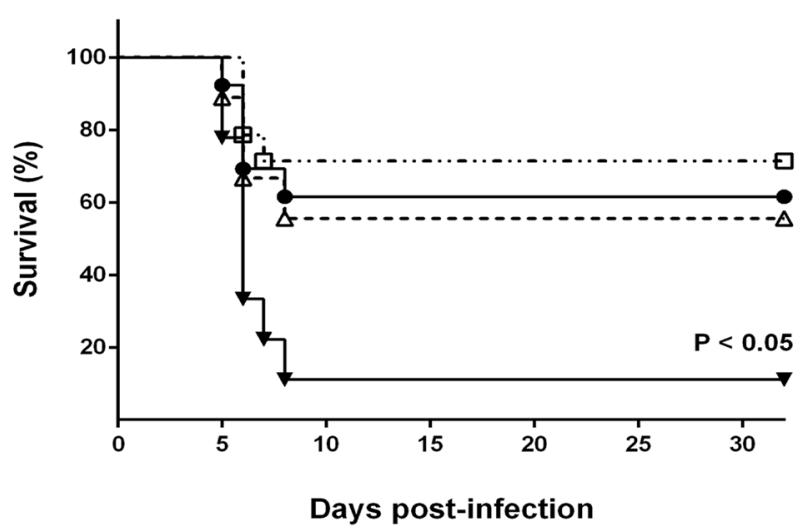

Figure 4. Effect of TLR ligands administration on survival of MHV-infected mice. Data are taken from three independent experiments, using 9 - 14 animals for any treatment. Symbols are as follows: MHV (•); Poly (I:C) + MHV $(\square)$; Loxoribine $+\operatorname{MHV}(\Delta)$ and $\mathrm{CpG}+\mathrm{MHV}(\boldsymbol{\nabla})$. In controls (animals without any treatment) and in mice inoculated only with the TLR ligands the survival was $100 \%$ (data not shown). Survival was monitored daily for up to five weeks. The Kaplan-Meier test was utilized to compare the differences in mortality rates between groups $\left({ }^{*} \mathrm{P}<0.05\right)$.

stimulate TLR7 or CpG (ODN 1826), the ligand of TLR9. To examine the effects of the three TLR ligands we measured the levels of plasma transaminases, anti-MHV Ab, Ig concentration, autoAb to FAH as well as to liver and kidney tissues, uric acid liberation and mouse survival. The three ligands were also administered alone to non-infected animals.

MHV-infected mice inoculated with Poly (I:C) had lower levels of plasma transaminases, serum Ig and uric acid than MHV-infected animals, but developed a remarkable amount of autoAb to kidney tissue, including auto Ab to FAH. However, Poly (I:C) did not affect mouse survival, indicating that autoAb did not produce any pathological effect. Thus, the whole data suggest some protective role of TLR3 stimulation on MHV-infection. No effect was seen when only Poly (I:C) was administered.

The putative defensive effect of Poly (I:C) described herein correlated with a similar "in vitro" activity of the TLR3-ligand on MHV-infected J774A.1 murine macrophages [22]. Thus, Mazaleuskaya et al. [22] found that pre-stimulation of TLR3 with Poly (I:C) hindered MHV infection through induction of IFN- $\beta$ in macrophages, demonstrating that activation of TLR3 with the synthetic ligand mediated antiviral immunity that diminishes virus production [22]. It was also reported that Poly (I:C) could emulate viral infection and NK cell-mediated liver injury [23] but, under our experimental conditions, Poly (I:C) administration did not induce any pathological effect on mice despites the induction of some anti-kidney autoAb. These contradictory results could be explained by either the dose of ligand used and/or the shorter time of the observations, hours instead of days as in He et al. [23] experiments.

Treatment of MHV-infected mice by Loxoribine, the ligand for TLR7, produced only a sharp decrease of serum Ig and a slight decrease of uric acid levels. The lack of important Loxoribine effects was rather surprising, since TLR7 has been described as an innate signaling receptor that recognizes single-stranded viral RNA and is activated by viruses that cause persistent infections [24]. One possibility is that Loxoribine was not the satisfactory ligand to stimulate TLR7 activity in our model of MHV infection, as shown by Rajagopal et al. [25] using different experimental procedures.

The TLR9 ligand, CpG, showed deleterious effects on MHV-infected mice, since survival of animals dramatically dropped to $11 \%$. AutoAb and uric acid release were not affected, whereas transaminases were elevated, even in spite of the lack of statistical significance because of the death of various mice. On the contrary, CpG significantly decreased serum Ig. In the same way, it has been reported that TLR9 stimulation promotes the accumulation and activation of hepatic $\mathrm{CD} 4^{+}$NKT cells by Kupffer cells and that pre-treatment with CpG aggravates Concanavalin A-induced hepatitis [26].

How to reconcile the fact that TLR9 recognizes DNA with the pathological effect of CpG on a RNA-virus infection? One possibility is that proposed by Kaisho [27], CpG motifs are found in mammalian DNA, although 
their frequency is much lower than in microorganism-derived DNA. Thus, since TLR9 is localized in the endoplasmic reticulum and can migrate into endosomes, where uninfected host-derived cells can be incorporated, TLR9 should have the potential ability to provoke immune responses against self nucleic acids [27]. Another option is to take into account the role of HMGB1, liberated by MHV-infection as shown previously [9] [12], in infection-induced inflammation. In fact, it was reported that HMGB1 could bind to LPS, CpG, viral RNA and IL-1, significantly increasing its inflammatory activity [28].

Main results presented here suggest that MHV effects are related to both TLR3 and TLR9. TLR3 activation by Poly (I:C), should protect the animals against the infection trough the liberation of Type I interferons whereas CpG would synergize the MHV activity thus enhancing the deleterious viral effects. Remarkably, the three ligands, producing different effects on animal survival and other parameters shown herein, decreased serum Ig, indicating an inhibition of the polyclonal activation produced by the virus. To our knowledge, this effect was not described in the literature, but may be related to the fact that TLR are also present in B-cells [16].

TLR agonists are being tested in vaccines against hepatitis $C$ and influenza as well as in allergic rhinitis and certain cancers [14]. TLR 3, 4, 7, 8 and 9 are all validated targets for cancer and a number of companies are developing agonists and vaccine adjuvants [29]. Thus, although the prospect of targeting TLRs in multiple pathologies continues to hold much promise, our observations suggest that $\mathrm{CpG}$ should be kept away from treating people under viral infections, mainly hepatotropic agents.

\section{Acknowledgements}

The authors are indebted to Dr. Pierre L. Masson (de Duve Institute, Université catholique de Louvain, Brussels, Belgium) for helpful discussions and critical revision of the manuscript. This work was supported by Consejo Nacional de Investigaciones Científicas y Técnicas (CONICET) and Universidad de Buenos Aires (UBA).

\section{References}

[1] Godfraind, C., Holmes, K.V. and Coutelier, J.-P. (1995) Thymus Involution Induced by Mouse Hepatitis Virus A59 in BALB/c Mice. Journal of Virology, 69, 6541-6547.

[2] Coutelier, J.-P., van der Logt, J.T., Heessen, F.W., Warnier, G. and Van Snick, J. (1987) IgG2a Restriction of Murine Antibodies Elicited by Viral Infections. Journal of Experimental Medicine, 165, 64-69. http://dx.doi.org/10.1084/jem.165.1.64

[3] Lavi, E., Gilden, D.H., Wroblewska, Z., Rorke, L.B. and Weiss, S.R. (1984) Experimental Demyelination Produced by the A59 Strain of Mouse Hepatitis Virus. Neurology, 34, 597-603. http://dx.doi.org/10.1212/WNL.34.5.597

[4] Mathieu, P.A., Gómez, K.A., Coutelier, J.-P. and Retegui, L.A. (2001) Identification of Two Liver Proteins Recognized by Autoantibodies Elicited in Mice Infected with Mouse Hepatitis Virus A59. European Journal of Immunology, 31, 1447-1455. http://dx.doi.org/10.1002/1521-4141(200105)31:5<1447::AID-IMMU1447>3.0.CO;2-6

[5] Duhalde-Vega, M., Loureiro, M.E., Mathieu, P.A. and Retegui, L.A. (2006) The Peptide Specificities of the Autoantibodies Elicited by Mouse Hepatitis Virus A59. Journal of Autoimmunity, 27, 203-209. http://dx.doi.org/10.1016/j.jaut.2006.09.003

[6] Duhalde-Vega, M., Aparicio, J.L. and Retegui, L.A. (2009) Fine Specificity of Autoantibodies Induced by Mouse Hepatitis Virus A59. Viral Immunology, 22, 287-294. http://dx.doi.org/10.1089/vim.2009.0019

[7] Mathieu, P.A., Gómez, K.A., Coutelier, J.-P. and Retegui, L.A. (2004) Sequence Similarity and Structural Homologies Are Involved in the Autoimmune Response Elicited by Mouse Hepatitis Virus A59. Journal of Autoimmunity, 23, 117-126. http://dx.doi.org/10.1016/j.jaut.2004.05.006

[8] Matzinger, P. (2002) The Danger Model: A Renewed Sense of Self. Science, 296, 301-305. http://dx.doi.org/10.1126/science.1071059

[9] Duhalde-Vega, M. and Retegui, L.A. (2011) Uric Acid and HMGB1 Are Involved in the Induction of Autoantibodies Elicited in Mice Infected with Mouse Hepatitis Virus A59. Autoimmunity, 44, 631-640. http://dx.doi.org/10.3109/08916934.2011.579927

[10] Aparicio, J.L., Duhalde-Vega, M., Loureiro, M.E. and Retegui, L.A. (2009) The Autoimmune Response Induced by Mouse Hepatitis Virus A59 Is Expanded by an Hepatotoxic Agent. International Immunopharmacology, 9, 627-631. http://dx.doi.org/10.1016/j.intimp.2009.02.006

[11] Alexander, J., del Guercio, M.-F., Frame, B., Maewal, A., Sette, A., Nahm, M.H. and Newman, M.J. (2004) Development of Experimental Carbohydrate-Conjugate Vaccines Composed of Streptococcus pneumonia Capsular Polysaccharides and the Universal Helper T-Lymphocyte Epitope (PADRE). Vaccine, 22, 2362-2367. 
http://dx.doi.org/10.1016/j.vaccine.2003.11.061

[12] Aparicio, J.L., Peña, C. and Retegui, L.A. (2011) Autoimmune Hepatitis-Like Disease in C57BL/6 Mice Infected with Mouse Hepatitis Virus A59. International Immunopharmacology, 11, 1591-1598. http://dx.doi.org/10.1016/j.intimp.2011.05.020

[13] Carty, M. and Bowie, A.G. (2010) Recent Insights into the Role of Toll-Like Receptors in Viral Infection. Clinical and Experimental Immunology, 161, 397-406. http://dx.doi.org/10.1111/j.1365-2249.2010.04196.x

[14] Connolly, D.J. and O’Neill, L.A.J. (2012) New Developments in Toll-Like Receptor Targeted Therapeutics. Current Opinion in Pharmacology, 12, 510-518. http://dx.doi.org/10.1016/j.coph.2012.06.002

[15] Kawai, T. and Akira, S. (2010) The Role of Pattern-Recognition Receptors in Innate Immunity: Update on Toll-Like Receptors. Nature Immunology, 11, 373-384. http://dx.doi.org/10.1038/ni.1863

[16] Kawai, T. and Akira, S. (2011) Toll-Like Receptors and Their Crosstalk with Other Innate Receptors in Infection and Immunity. Immunity, 34, 637-650. http://dx.doi.org/10.1016/j.immuni.2011.05.006

[17] Coutelier, J.-P., Coulie, P.G., Wauters, P., Heremans, H. and van der Logt, J.T.M. (1990) In Vivo Polyclonal B-Lymphocyte Activation Elicited by Murine Viruses. Journal of Virology, 64, 5383-5388.

[18] Gustot, T., Lemmers, A., Moreno, C., Nagy, N., Quertinmont, E., Nicaise, C., Franchimont, D., Louis, H., Devière, J. and Le Moine, O. (2006) Differential Liver Sensitization to Toll-Like Receptor Pathways in Mice with Alcoholic Fatty Liver. Hepatology, 43, 989-1000. http://dx.doi.org/10.1002/hep.21138

[19] Hayashia, T., Graya, C.S., Chana, M., Tawataoa, R.I., Ronacherb, L., McGargillc, M.A., Dattad, S.K., Carsona, D.A. and Corrb, M. (2009) Prevention of Autoimmune Disease by Induction of Tolerance to Toll-Like Receptor 7. Proceedings of the National Academy of Sciences of the United States of America, 24, 2764-2769. http://dx.doi.org/10.1073/pnas.0813037106

[20] Bradford, M.M. (1976) A Rapid and Sensitive Method for the Quantification of Microgram Quantities of Protein Utilizing the Principle of Protein-Dye Binding. Analytical Biochemistry, 72, 248-254. http://dx.doi.org/10.1016/0003-2697(76)90527-3

[21] Liu, G. and Zhao, Y. (2007) Toll-Like Receptors and Immune Regulation: Their Direct and Indirect Modulation on Regulatory CD4 ${ }^{+}$CD25 ${ }^{+}$T Cells. Immunology, 122, 149-156. http://dx.doi.org/10.1111/j.1365-2567.2007.02651.X

[22] Mazaleuskaya, L., Veltrop, R., Ikpeze, N., Martin-Garcia, J. and Navas-Martin, S. (2012) Protective Role of Toll-Like Receptor 3-Induced Type I Interferon in Murine Coronavirus Infection of Macrophages. Viruses, 4, 901-923. http://dx.doi.org/10.3390/v4050901

[23] He, J., Lang, G., Ding, S. and Li, L. (2013) Pathological Role of Interleukin-17 in Poly I:C-Induced Hepatitis. PLoS ONE, 8, e73909. http://dx.doi.org/10.1371/journal.pone.0073909

[24] Walsh, K.B., Teijaro, J.R., Zuniga, E.I., Welch, M.J., Fremgen, D.M., Blackburn, S.D., von Tiehl, K.F., Wherry, E.J., Flavell, R.A. and Oldstone, M.B.A. (2012) Toll-Like Receptor 7 Is Required for Effective Adaptive Immune Responses that Prevent Persistent Virus Infection. Cell Host \& Microbe, 11, 643-653. http://dx.doi.org/10.1016/j.chom.2012.04.016

[25] Rajagopal, D., Paturel, C., Morel, Y., Uematsu, S., Akira, S. and Diebold, S.S. (2010) Plasmacytoid Dendritic CellDerived Type I Interferon Is Crucial for the Adjuvant Activity of Toll-Like Receptor 7 Agonists. Blood, 115, 19491957. http://dx.doi.org/10.1182/blood-2009-08-238543

[26] Jiang, W., Sun, R., Zhou, R., Wei, H. and Tian, Z. (2009) TLR-9 Activation Aggravates Concanavalin A-Induced Hepatitis via Promoting Accumulation and Activation of Liver CD4 ${ }^{+}$NKT Cells. Journal of Immunology, 182, 3768-3774. http://dx.doi.org/10.4049/jimmunol.0800973

[27] Kaisho, T. (2012) Pathogen Sensors and Chemokine Receptors in Dendritic Cell Subsets. Vaccine, 30, $7652-7657$. http://dx.doi.org/10.1016/j.vaccine.2012.10.043

[28] Yang, H. and Tracey, K.J. (2010) Targeting HMGB1 in Inflammation. Biochimica et Biophysica Acta, 1799, $149-156$. http://dx.doi.org/10.1016/j.bbagrm.2009.11.019

[29] Holldack, J. (2014) Toll-Like Receptors as Therapeutic Targets for Cancer. Drug Discovery Today, 19, 379-382. http://dx.doi.org/10.1016/j.drudis.2013.08.020 
Scientific Research Publishing (SCIRP) is one of the largest Open Access journal publishers. It is currently publishing more than 200 open access, online, peer-reviewed journals covering a wide range of academic disciplines. SCIRP serves the worldwide academic communities and contributes to the progress and application of science with its publication.

Other selected journals from SCIRP are listed as below. Submit your manuscript to us via either submit@scirp.org or Online Submission Portal.
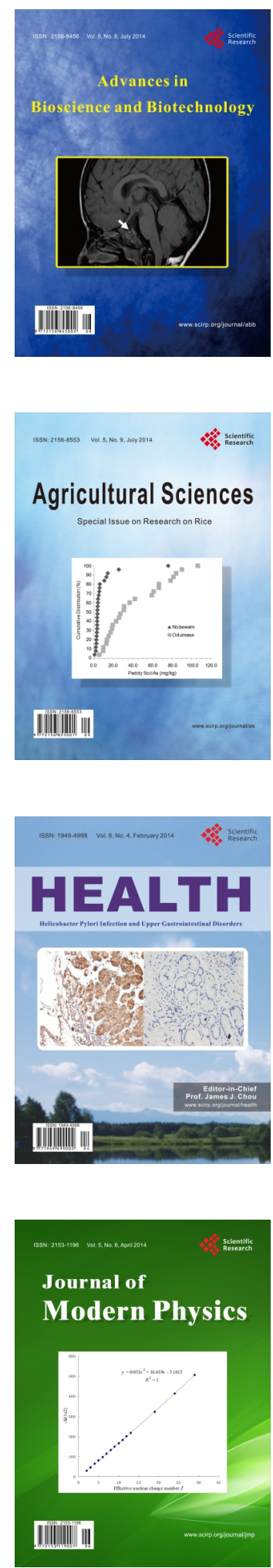
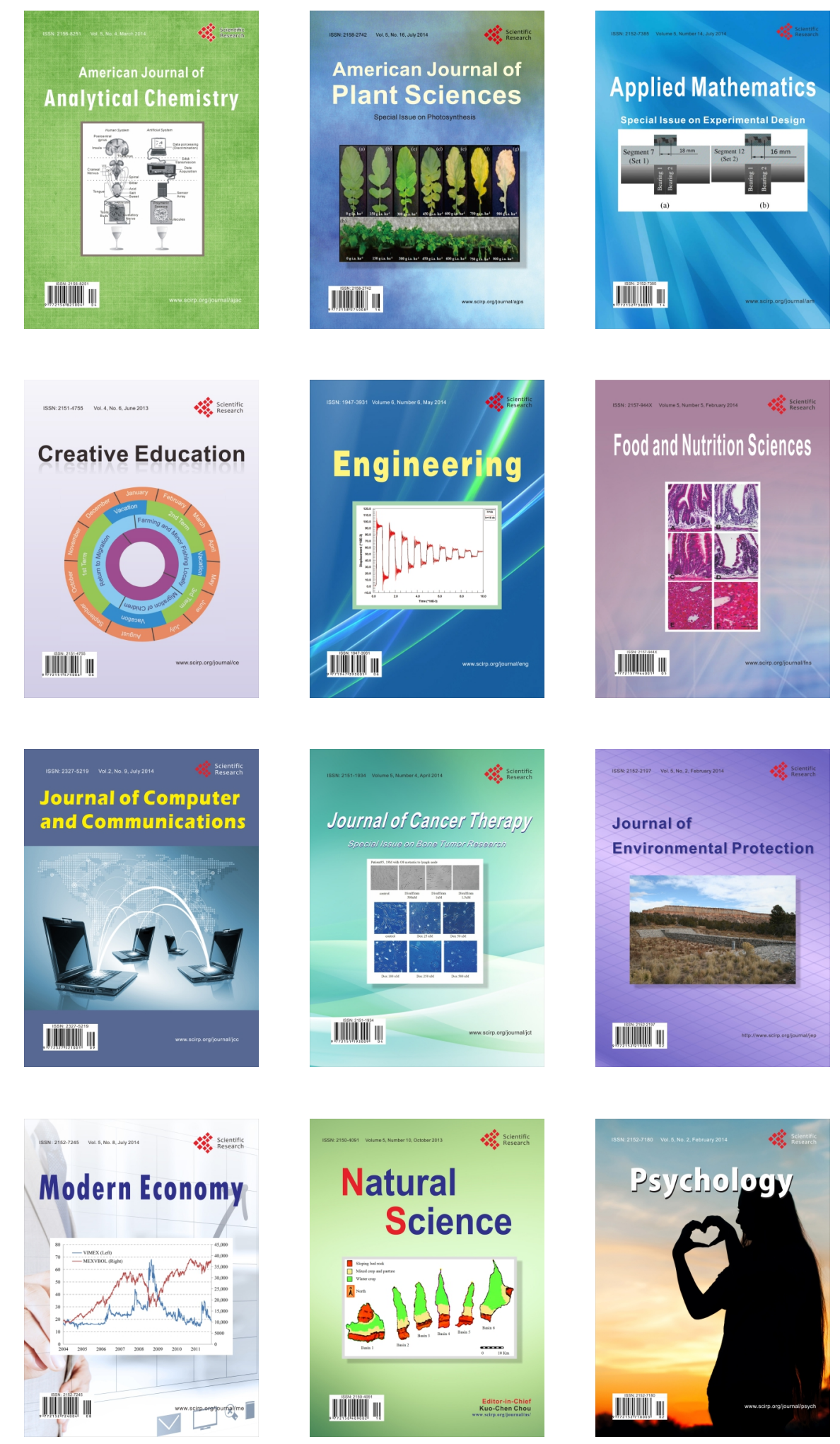